\title{
Association of objective sedentary behaviour and self-rated health in English older adults
}

Jason J. Wilson ${ }^{1,2^{*}{ }^{+}}$, Nicole E. Blackburn ${ }^{1,2+}{ }^{2}$, Rachel O'Reilly ${ }^{3}$, Frank Kee ${ }^{1,2}$, Paolo Caserotti ${ }^{4}$ and Mark A. Tully ${ }^{1,2,5}$

\begin{abstract}
Objective: Reducing sedentary behaviour (SB) might improve the health of older adults. However, we know little about how objectively measured SB impacts on self-rated health in older adults. We aimed to explore the associations between objectively measured SB and self-rated health in English older adults.

Results: A random sub-sample of older adults ( $\geq 65$ years old) from the 2008 Health Survey for England wore an ActiGraph GT1M accelerometer for 7 days. Self-rated health was measured using an item from the General Health Questionnaire. Linear regression and analysis of covariance were used to test the associations between percentage time spent in SB and mean daily minutes in SB and self-rated health (very good/good; fair; bad/very bad), adjusting for covariates. Valid accelerometry datasets were returned by 578 individuals. Significant negative associations between percentage time and mean daily minutes in SB and self-rated health were found. In particular, individuals spending reduced percentages of time being sedentary had higher self-rated health. In conclusion, SB appears to be associated with self-rated health in older people independently from MVPA. If longitudinal research could determine how changes in SB influence self-rated health as individuals' age, this might be an important lifestyle variable to target for health improvement.
\end{abstract}

Keywords: Sedentary behaviour, Accelerometer, Self-rated health, Older adults

\section{Introduction}

Physical activity (PA) promotes healthy ageing while inactivity is associated with elevated risks of chronic disease and all-cause mortality $[1,2]$. Some research suggests that regardless of levels of objectively assessed moderate-vigorous physical activity (MVPA), time spent in sedentary behaviour (SB) is an independent risk factor for ill health, morbidity and mortality [3-6]. Although a recent large meta-analysis suggests these risks are attenuated with 60-75 min of daily MVPA [7]. Inactivity refers to not meeting MVPA guidelines [2], while SB has been defined as "any waking behaviour characterised by an energy expenditure of $\leq 1.5$ metabolic equivalents while

\footnotetext{
*Correspondence: Jason.Wilson@qub.ac.uk

${ }^{\dagger}$ Jason J. Wilson and Nicole E. Blackburn contributed equally to this work

${ }^{1}$ Centre for Public Health, School of Medicine, Dentistry and Biomedical Sciences, Queen's University Belfast, Belfast, UK

Full list of author information is available at the end of the article
}

in a sitting or reclining posture" [8]. Therefore, irrespective of whether an individual meets the MVPA guidelines, prolonged periods of SB are likely to compromise health $[3,9,10]$.

The UK population is rapidly ageing, with 2015 figures suggesting there were over 11.6 million (17.8\%) aged $\geq 65$ years old [11]. Older adults are the most sedentary population group [12], hence they are at higher risk of developing various chronic health conditions. Most intervention studies conducted in older adults have focused on increasing MVPA [13, 14]. Interestingly, older adults who are either physically active or non-sedentary both exhibit improved functional fitness [15]. Thus, targeting sedentary lifestyles may provide an alternative approach to improving health outcomes [16].

It is important to monitor and assess population health status trends [17]. Self-rated health measures are extensively used in public health research [17-19] and are generally accepted as valid measures of health status in 
population studies, with lower ratings associated with increased morbidity and mortality [20-22]. Self-reported health assessments reflect an individual's perception of their own health status and are usually consistent with objective health measures $[18,22]$. SB can be measured using subjective (questionnaires) and objective tools (accelerometers) [23]. High levels of SB appear to be related to lower self-rated health [24-27]. However, most studies have used subjective SB tools which are subject to misclassification bias and recall bias; particularly in older adults [28]. One study has explored the association between objectively measured SB and health status in older adults [25]. However, this study sampled older adults living in retirement communities who may not represent the general older adult population and assessed health through numerous questionnaires. Single questions to assess health status are more practical, easier to interpret and likely to be used more widely in both research and clinical practice [29].

This study aims to explore the associations between objectively measured SB and self-rated health in English older adults using data from the Health Survey for England (2008). The hypothesis is that higher levels of SB will be associated with reduced self-rated health.

\section{Main text}

\section{Data collection}

The Health Survey for England is a repeat cross-sectional survey designed to monitor trends in health and healthrelated behaviours in a nationally representative and random sample of adults and children living in private English households. The Oxford Research Ethics Committee (reference 07/H0604/102) approved the survey. The 2008 report particularly focused on PA and fitness. A nurse visited each consenting participant to fill in questionnaires. In addition, a random sub-sample wore an ActiGraph GT1M accelerometer on the waist using an elastic belt for seven consecutive days during waking hours; allowing for a cross-sectional study. More details on recruitment methods and sampling strategy are contained in the main report [30]. Standardised outcome variables were produced from raw accelerometry data using KineSoft (3.0.98). Each participant's dataset was deemed valid if the accelerometer was worn $\geq 600 \mathrm{~min} /$ day for at least 4 days [31] with no minimum weekday/ weekend day criteria. Exclusion criteria included being immobile/wheelchair bound, having a latex allergy, recent abdominal surgery, failure to provide at least four valid days or were otherwise deemed unsuitable to wear the ActiGraph. Percentage time spent in SB and mean daily time in SB (i.e. $<200$ counts per minute from the vertical axis) were used as primary outcome measures with sleep-time being excluded.
Self-rated general health was measured using the relevant item in the 12-item General Health Questionnaire (GHQ-12) [32]. Participants were asked to rate their health using the following: very good, good, fair, bad and very bad. Small participant numbers in certain groups meant these were collapsed to three groups (i.e. very good/good, fair and bad/very bad).

\section{Statistical analysis}

Summary data are reported as mean (standard deviation) unless otherwise stated. Characteristics of respondents who returned a valid accelerometer reading were compared with those who did not using basic descriptive statistics (independent samples t-tests and Chi square). Linear regression analysis (adjusted for covariates) was used to assess the association of percentage time spent in SB (Model 1) and daily time spent in SB (Model 2) and self-rated health. Analysis of Covariance was used to compare the percentage and mean daily time in SB between three groups of participants according to their self-rated health, with Bonferroni correction. Age, sex, body mass index $\left(\mathrm{BMI} ; \mathrm{kg} / \mathrm{m}^{2}\right.$ ), education (university degree, secondary qualification or no qualification), total household income $(£)$, urban/rural classification (urban, suburban/town or village/hamlet/isolated dwelling), smoking status (never smoked, occasional smoker, regular smoker or current smoker), current alcohol drinker (yes/no), presence of long standing health conditions (yes/no) and mean daily minutes in MVPA (i.e.> 2019 counts per minute) were used as covariates. Analysis was conducted using SPSS v22 (IBM Corporation, USA), with statistical significance set at $\mathrm{p}<0.05$.

\section{Results}

From the original dataset containing 1250 older adults, 578 returned valid accelerometry datasets. Participants who returned a valid accelerometry dataset were significantly younger $(\mathrm{p}<0.001)$, more educated $(\mathrm{p}=0.016)$, were less likely to be female $(\mathrm{p}=0.006)$, more likely to currently drink alcohol $(\mathrm{p}=0.005)$ and had higher self-rated health $(\mathrm{p}<0.001)$ compared to those who did not return a valid dataset. No differences in terms of BMI $(p=0.867)$, total household income $(\mathrm{p}=0.082)$, urban/rural classification $(\mathrm{p}=0.316)$, smoking status $(\mathrm{p}=0.052)$ and presence of long standing health conditions $(\mathrm{p}=0.363)$ were identified between these groups. Table 1 provides the characteristics of the valid sample.

Before adjustment for covariates, there was a negative trend between self-rated health and percentage time and daily time in SB in the sample of 578 participants (Table 2). Due to missing data, the sample size for the analysis reduced to 435 participants. In Model 
Table 1 Descriptive statistics for included participants with valid accelerometer data $(n=578)$

\begin{tabular}{|c|c|}
\hline Variables $(n=578)$ & Mean (SD) \\
\hline Daily time in sedentary behaviour (min/day) & $617.61(83.41)$ \\
\hline Percentage of time in sedentary behaviour (\%) & $75.47(9.45)$ \\
\hline $\begin{array}{l}\text { Daily time in moderate-vigorous physical activity (min/ } \\
\text { day) }\end{array}$ & $14.97(19.73)$ \\
\hline $\begin{array}{l}\text { Percentage of time in moderate-vigorous physical activ- } \\
\text { ity (\%) }\end{array}$ & $1.79(2.32)$ \\
\hline \multicolumn{2}{|l|}{ Self-rated health, $n(\%)$} \\
\hline Very good/good & $367(63.5)$ \\
\hline Fair & $158(27.3)$ \\
\hline Bad/very bad & $53(9.2)$ \\
\hline Age (years) & $73.69(6.38)$ \\
\hline \multicolumn{2}{|l|}{$\operatorname{Sex}, n(\%)$} \\
\hline Males & $274(47.4)$ \\
\hline Females & $304(52.6)$ \\
\hline Body mass index $\left(\mathrm{kg} / \mathrm{m}^{2}\right)^{*}$ & $28.13(4.84)$ \\
\hline \multicolumn{2}{|l|}{ Urban/rural classification, $n$ (\%) } \\
\hline Urban & $449(77.7)$ \\
\hline Suburban/town & $46(8.0)$ \\
\hline Village/hamlet/isolated dwelling & $83(14.4)$ \\
\hline \multicolumn{2}{|l|}{ Smoking status, n (\%) } \\
\hline Never smoked & $239(41.3)$ \\
\hline Occasional smoker & $35(6.1)$ \\
\hline Regular smoker & $249(43.1)$ \\
\hline Current smoker & $55(9.5)$ \\
\hline \multicolumn{2}{|l|}{ Current alcohol drinker, n (\%) } \\
\hline Yes & $459(79.4)$ \\
\hline No & $119(20.6)$ \\
\hline \multicolumn{2}{|l|}{ Long standing illness, n (\%) } \\
\hline No condition present & $401(69.4)$ \\
\hline Condition present & 177 (30.6) \\
\hline
\end{tabular}

1 using percentage time in $\mathrm{SB}$, a significant negative association was found $\left(\mathrm{p}=0.003\right.$; adjusted $\left.\mathrm{r}^{2}=0.410\right)$
(Table 2). In Model 2 using daily time in SB, a significant negative association was also found but to a lesser extent $\left(\mathrm{p}<0.001\right.$; adjusted $\left.\mathrm{r}^{2}=0.177\right)$ (Table 2).

After adjustment, individuals who rated their health as very good/good spent $3.56 \%$ [ $95 \%$ confidence interval $(95 \% \mathrm{CI})-5.72$ to -1.41$]$ and $5.66 \%$ (95\% CI -8.92 to $-2.40)$ proportionally less time in SB compared to fair and bad/very bad (both $\mathrm{p}<0.001$ ) (Table 3). Considering daily times, individuals rating their health as very good/good spent significantly less time in SB than fair (-29.23 $\mathrm{min} /$ day; $95 \% \mathrm{CI}-51.62$ to -6.83$)$ but not bad/ very bad (31.52 min per day; $95 \% \mathrm{CI}-65.38$ to 2.34 ).

\section{Discussion}

This is the first study to explore associations between objectively measured SB and self-rated health in freeliving older adults. A significant negative association between SB and self-rated health was found after accounting for important covariates.

These results support other research exploring associations between SB and self-rated health in older adult populations. For example, a cross-sectional study of older adults in Latin America found that those in the highest sitting time categories were more likely to report poor self-rated health [24]. This finding was replicated in other American older adult populations [25, 26]. Davies and colleagues [27] have demonstrated that after controlling for confounders, increased screen-time in older adults exacerbates the impact of low MVPA levels on the likelihood of self-rating their health as poor or fair. A large prospective cohort study in adults aged $\geq 45$ years old measured self-rated health as a confounding variable when exploring the association between sitting time and all-cause mortality [33]. The authors highlighted that individuals with lower self-rated health appeared to be the most sedentary (without confounder adjustment). More research has been conducted on PA, with studies showing that better self-rated health among adults

Table 2 Sedentary behaviour in categories of self-rated health before and after adjustment for covariates

\begin{tabular}{|c|c|c|}
\hline Self-rated general health $(n=578)$ & $\begin{array}{l}\text { Mean percentage time spent in sedentary } \\
\text { behaviour (\%) }\end{array}$ & $\begin{array}{l}\text { Mean daily tim } \\
\text { in sedentary b } \\
(\min )\end{array}$ \\
\hline \multicolumn{3}{|l|}{ Before adjustment for covariates [mean (SD)] } \\
\hline Very good/good (mins/day), $n=367$ & $73.19(8.79)$ & $602.41(77.89)$ \\
\hline Fair (mins/day), $n=158$ & $78.45(9.40)$ & $639.23(87.86)$ \\
\hline $\mathrm{Bad} /$ very bad (mins/day), $\mathrm{n}=53$ & $82.40(8.21)$ & $658.36(80.30)$ \\
\hline \multicolumn{3}{|l|}{ After adjustment for covariates [mean (SE)] } \\
\hline Very good/good (\%), $n=277$ & $73.89(0.46)$ & $605.76(4.80)$ \\
\hline Fair (\%), $n=119$ & $77.44(0.71)$ & $634.98(7.39)$ \\
\hline Bad/very bad (\%), n=39 & $79.57(1.23)$ & $637.28(12.75)$ \\
\hline
\end{tabular}


Table 3 Pairwise comparison of sedentary behaviour between groups after adjustment for covariates

\begin{tabular}{|c|c|c|c|c|}
\hline \multicolumn{2}{|c|}{ Self-rated general health $(n=435)$} & \multirow[t]{2}{*}{ Mean difference } & \multirow[t]{2}{*}{ 95\% $\mathrm{Cl}$ for difference } & \multirow[t]{2}{*}{ p-value } \\
\hline \multicolumn{2}{|c|}{ Percentage time spent in sedentary behaviour (\%) } & & & \\
\hline \multirow[t]{2}{*}{ Very good/good $(n=277)$} & Fair $(n=119)$ & -3.56 & -5.72 to -1.41 & $<0.001^{*}$ \\
\hline & Bad/very bad $(n=39)$ & -5.66 & -8.92 to -2.40 & $<0.001^{*}$ \\
\hline Fair $(n=119)$ & Bad/very bad $(n=39)$ & -2.10 & -5.37 to 1.17 & 0.371 \\
\hline \multicolumn{5}{|c|}{ Daily time spent in sedentary behaviour (min/day) } \\
\hline \multirow[t]{2}{*}{ Very good/good $(n=277)$} & Fair $(n=119)$ & -29.23 & -51.62 to -6.83 & $0.005^{*}$ \\
\hline & Bad/very bad $(n=39)$ & -31.52 & -65.38 to 2.34 & 0.077 \\
\hline Fair $(n=119)$ & Bad/very bad $(n=39)$ & -2.30 & -36.26 to 31.67 & 1.000 \\
\hline
\end{tabular}

* $\mathrm{p}<0.05$ using Bonferroni method

appears to be related to a sufficiently active lifestyle [34-37].

These associations are unsurprising considering that SB has consistently been shown to be an independent risk factor for physical and psychological health conditions such as type II diabetes, cancer and anxiety [3, 9, $38,39]$. Qualitative research has also explored the individual motivators and impacts of SB. Individuals have highlighted how prolonged sitting causes increased pain, stiffer joints and more depressed feelings [40]. Older adults taking part in a SB reduction intervention identified positive physical impacts such as improved chronic pain management, balance and sleep quality with positive psychological impacts including feelings of better health, less perceived fatigue and enhanced concentration [6].

Bailis et al. suggest that self-rated health does not simply involve spontaneous assessments of one's health status and related practices, but is rather an enduring self-concept (i.e. regulated by efforts to achieve healthrelated goals) [41]. Additionally, a unified conceptual model has been proposed which describes the reflective process an individual goes through when self-rating their health [21]. One aspect of this reflection suggests that bodily sensations provide important signs of physiological imbalance unique to the individual. Our findings and those from other studies would suggest that SB fits well into this model. For example, a retired individual reflecting on their health status may consider how they were less sedentary while working, compared to now; resulting in increased feelings of stiffness and fatigue. Thus, selfrated health is a complex phenotype that may be variably impacted by different health problems and their functional consequences so these reflections are likely to have an important influence on how individuals rate their current health status [42].

An interesting finding were the different results found when considering percentage time versus mean daily time in SB. After adjustment, percentage time in SB appeared to be a strong predictor of self-rated health whereas daily time in SB gave mixed results. This is an important consideration for future research as participants wear accelerometers for a range of hours across their daily waking time. For example, participant one may be sedentary for $10 \mathrm{~h}$ per day versus participant two for $13 \mathrm{~h}$ per day. However, participant one may be sedentary for $90 \%$ of their waking day versus participant two who is sedentary for $75 \%$. Therefore, it is important to consider SB relatively to wear time.

In conclusion, this study suggests that SB could be a novel and important modifiable lifestyle variable to target for health improvement. For researchers and clinicians, the current study findings are important. Patients providing more negative ratings of their health are likely to spend more time in SB. Therefore, helping such patients' target reductions in SB may be an important step to take for health improvement. Future research should plan for long-term follow-up in order to determine how changes in SB influence self-rated health as individuals' age.

\section{Limitations}

Activity monitors were only implemented in the 2008 Health Survey for England and have not been subsequently used. This means a cross-sectional design, meaning causality cannot be established. Combining some of the self-rated health categories was not ideal due to insufficient numbers in certain categories. Almost 54\% of the sample was lost due to exclusions of invalid data. The valid sample were younger, more educated and had higher self-rated health; potentially reducing the representativeness of the findings. Missingness of confounding variables from some participants reduced the sample size. It was not possible to impute values due to the extent of missing data. Reporting heterogeneity may also have occured (i.e. participants may have reported health differently depending upon perceptions of their own health) [43]. All potential confounders were possibly not accounted for (e.g. cardiovascular fitness and depression) which have previously been shown to be important 
predictors of self-rated health [35, 44]. The association also appeared to be non-linear in nature.

An important strength of this study was that SB was objectively measured, unlike many other studies which have used self-report instruments. These are often subject to recall and social-desirability bias. The sample was drawn from a large, representative cohort, and levels of MVPA have been controlled for in the analysis.

\section{Abbreviations}

95\% Cl: 95\% confidence interval; BMI: body mass index; MVPA: moderatevigorous physical activity; $\mathrm{kg} / \mathrm{m}^{2}$ : kilograms per metre squared; PA: physical activity; SB: sedentary behaviour; SD: standard deviation; SE: standard error.

\section{Authors' contributions}

Conceptualisation: JJW, NEB, RO'R, FK, PC, MAT. Methodology: JJW, NEB, RO'R, FK, PC, MAT. Formal analysis: JJW, MAT. Writing-original draft preparation: JJW, NEB, RO'R, MAT. Writing-review and editing: JJW, NEB, RO'R, FK, PC, MAT. All authors read and approved the final manuscript.

\begin{abstract}
Author details
${ }^{1}$ Centre for Public Health, School of Medicine, Dentistry and Biomedical Sciences, Queen's University Belfast, Belfast, UK. ${ }^{2}$ UKCRC Centre of Excellence for Public Health, Belfast, UK. ${ }^{3}$ Active Belfast, Belfast Health Development Unit, Public Health Agency, Belfast, UK. ${ }^{4}$ Department of Sports Science and Clinical Biomechanics, Syddansk Universitet, Campusvej 55, 5230 Odense M, Denmark ${ }^{5}$ Institute of Mental Health Sciences, School of Health Sciences, Ulster University, Newtownabbey, UK.
\end{abstract}

\section{Acknowledgements}

The authors would like to thank all participants who took part in the 2008 Health Survey for England, Dr Chris Cardwell (Queen's University Belfast) for statistical support and also Mrs Nichola Laird (Queen's University Belfast) for her support during the SITless research project.

The work described in this publication was part of the SITLESS project, supported and funded by the European Union program Horizon 2020 (H2020Grant 634270). Consortium members of the participating organisations of the SITLESS project: Antoni Salvà Casanovas, Àlex Domingo, Marta Roqué and Laura Coll-Planas: Health and Ageing Foundation of the Autonomous University of Barcelona, Spain; Maria Giné-Garriga, Miriam Guerra-Balic, Carme Martin-Borràs, Javier Jerez-Roig, Guillermo R Oviedo, Marta Santiago-Carrés, Oriol Sansano and Guillermo Varela: Faculty of Psychology, Education and Sport Sciences Blanquerna, Ramon Llull University, Barcelona, Spain; Emma McIntosh and Manuela Deidda: Health Economics and Health Technology Assessment, University of Glasgow, UK; Dietrich Rothenbacher, Michael Denkinger, Katharina Wirth, Dhayana Dallmeier and Jochen Klenk: Institute of Epidemiology and Medical Biometry, Ulm University, Germany; Mark A Tully, Frank Kee, Jason J Wilson and Nicole E Blackburn: UKCRC Centre of Excellence for Public Health (NI), Centre for Public Health, School of Medicine, Dentistry and Biomedical Sciences, Queen's University Belfast, UK; Paolo Caserotti and Mathias Skjødt: Department of Sport Science and Clinical Biomechanics, University of South Denmark, Denmark; Guillaume Lefebvre: SIEL, Sport initiative et Loisir Bleu association, Straßbourg, France; Denise González: SIEL, Sport initiative et Loisir Bleu association, Barcelona, Spain.

\section{Competing interests}

The authors declare that they have no competing interests.

\section{Availability of data and materials}

Data are available from the Health and Social Care Information Centre for researchers who meet the criteria for access to confidential data.

\section{Consent for publication}

Not applicable.

\section{Ethics approval and consent to participate}

The Health Survey for England was conducted with the written informed consent of all participants, and was approved by the Oxford A Research Ethics Committee (reference 07/H0604/102).

\section{Funding}

Jason J Wilson, Nicole E. Blackburn, Frank Kee, Paolo Caserotti and Mark A. Tully are supported and funded by the European Union program Horizon 2020 (H2020-Grant 634270) as part of the SITless consortium. Frank Kee and Mark A Tully are also partially funded by the Centre of Excellence for Public Health (Northern Ireland). The Centre of Excellence for Public Health (Northern Ireland) (Grant Number RES-590-28-001) is a UKCRC Public Health Research Centre of Excellence. Funding from the British Heart Foundation, Cancer Research UK, Economic and Social Research Council, Medical Research Council, Research and Development Office for the Northern Ireland Health and Social Services, and the Wellcome Trust, under the auspices of the UK Clinical Research Collaboration, is gratefully acknowledged. The authors declare that they have no competing interests.

\section{Publisher's Note}

Springer Nature remains neutral with regard to jurisdictional claims in published maps and institutional affiliations.

Received: 9 November 2018 Accepted: 4 January 2019

Published online: 11 January 2019

\section{References}

1. Katzmarzyk PT, Church TS, Craig CL, Bouchard C. Sitting time and mortality from all causes, cardiovascular disease, and cancer. Med Sci Sports Exerc. 2009:41(5):998-1005.

2. De Rezende LF, Lopes MR, Rey-López JP, Matsudo VK, do Carmo Luiz O. Sedentary behavior and health outcomes: an overview of systematic reviews. PLoS ONE. 2014;9(8):e105620.

3. Bankoski A, Harris TB, McClain JJ, Brychta RJ, Caserotti P, Chen KY, et al. Sedentary activity associated with metabolic syndrome independent of physical activity. Diabetes Care. 2011;34(2):497-503.

4. Koster A, Caserotti P, Patel KV, Matthews CE, Berrigan D, Van Domelen $\mathrm{DR}$, et al. Association of sedentary time with mortality independent of moderate to vigorous physical activity. PLoS ONE. 2012;7(6):e37696.

5. Wilmot EG, Edwardson CL, Achana FA, Davies MJ, Gorely T, Gray LJ, et al. Sedentary time in adults and the association with diabetes, cardiovascular disease and death: systematic review and meta-analysis. Diabetologia. 2012;14(55):2895-905.

6. Greenwood-Hickman MA, Renz A, Rosenberg DE. Motivators and barriers to reducing sedentary behavior among overweight and obese older adults. Gerontol. 2016;56(4):660-8.

7. Ekelund U, Steene-Johannessen J, Brown WJ, Fagerland MW, Owen N, Powell KE, Bauman A, Lee IM, Lancet Physical Activity Series 2 Executive Committee; Lancet Sedentary Behaviour Working Group. Does physical activity attenuate, or even eliminate, the detrimental association of sitting time with mortality? A harmonised metaanalysis of data from more than 1 million men and women. Lancet. 2016;388(10051):1302-10.

8. Barnes J, Behrens TK, Benden ME, Biddle S, Bond D, Brassard P, et al. Letter to the Editor: standardized use of the terms" sedentary" and" sedentary behaviours". Appl Physiol Nutr Metab. 2012;37(3):540-2.

9. Owen N, Healy GN, Matthews CE, Dunstan DW. Too much sitting: the population-health science of sedentary behavior. Exerc Sport Sci Rev. 2010;38(3):105-13. 
10. Thorp AA, Owen N, Neuhaus M, Dunstan DW. Sedentary behaviors and subsequent health outcomes in adults: a systematic review of longitudinal studies, 1996-2011. Am J Prev Med. 2011;41(2):207-15.

11. Overview of the UK population. London: Office for National Statistics; 2017. https://www.ons.gov.uk/peoplepopulationandcommunity/popul ationandmigration/populationestimates/articles/overviewoftheukpopul ation/mar2017. Accessed 29 May 2017.

12. Matthews CE, Chen KY, Freedson PS, Buchowski MS, Beech BM, Pate RR, et al. Amount of time spent in sedentary behaviors in the United States, 2003-2004. Am J Epidemiol. 2008;167(7):875-81.

13. Taylor AH, Cable NT, Faulkner G, Hillsdon M, Narici M, Van Der Bij AK. Physical activity and older adults: a review of health benefits and the effectiveness of interventions. J Sports Sci. 2004;22(8):703-25.

14. Müller AM, Khoo S. Non-face-to-face physical activity interventions in older adults: a systematic review. Int J Behav Nutr Phys Act. 2014;10(11):35.

15. Santos DA, Silva AM, Baptista F, Santos R, Vale S, Mota J, et al. Sedentary behavior and physical activity are independently related to functional fitness in older adults. Exp Gerontol. 2012;47(12):908-12.

16. Sparling PB, Howard BJ, Dunstan DW, Owen N. Recommendations for physical activity in older adults. BMJ. 2015;21(350):h100.

17. Miilunpalo S, Vuori I, Oja P, Pasanen M, Urponen H. Self-rated health status as a health measure: the predictive value of self-reported health status on the use of physician services and on mortality in the working-age population. J Clin Epidemiol. 1997;50(5):517-28.

18. Wu S, Wang R, Zhao Y, Ma X, Wu M, Yan X, et al. The relationship between self-rated health and objective health status: a population-based study. BMC Public Health. 2013;9(13):320.

19. Au N, Johnston DW. Self-assessed health: what does it mean and what does it hide? Soc Sci Med. 2014;30(121):21-8.

20. Idler EL, Benyamini Y. Self-rated health and mortality: a review of twentyseven community studies. J Health Soc Behav. 1997;38(1):21-37.

21. Jylhä M. What is self-rated health and why does it predict mortality? Towards a unified conceptual model. Soc Sci Med. 2009;69(3):307-16.

22. Harris SE, Hagenaars SP, Davies G, Hill WD, Liewald D, Ritchie SJ, et al. Molecular genetic contributions to self-rated health. Int J Epidemiol. 2016:46:dyw219.

23. Stamatakis E, Davis M, Stathi A, Hamer M. Associations between multiple indicators of objectively-measured and self-reported sedentary behaviour and cardiometabolic risk in older adults. Prev Med. 2012;54(1):82-7.

24. Meneguci J, Sasaki JE, da Silva Santos Á, Scatena LM, Damião R. Sociodemographic, clinical and health behavior correlates of sitting time in older adults. BMC Public Health. 2015;31(15):65.

25. Rosenberg DE, Bellettiere J, Gardiner PA, Villarreal VN, Crist K, Kerr J. Independent associations between sedentary behaviors and mental, cognitive, physical, and functional health among older adults in retirement communities. Gerontol A Biol Sci Med Sci. 2016;71(1):78-83.

26. Millstein RA, Hoerster KD, Rosenberg DE, Nelson KM, Reiber G, Saelens BE. Individual, social, and neighborhood associations with sitting time among veterans. J Phys Act Health. 2016;13(1):30-5.

27. Davies CA, Vandelanotte C, Duncan MJ, Van Uffelen JG. Associations of physical activity and screen-time on health related quality of life in adults. Prev Med. 2012:55(1):46-9.
28. Jefferis BJ, Sartini C, Ash S, Lennon LT, Wannamethee SG, Whincup PH. Validity of questionnaire-based assessment of sedentary behaviour and physical activity in a population-based cohort of older men; comparisons with objectively measured physical activity data. Int J Behav Nutr Phys Act. 2016;13:14

29. Bowling A. Just one question: if one question works, why ask several? J Epidemiol Community Health. 2005;59:342-5.

30. Joint Health Surveys Unit. The Health Survey for England 2008_-physical activity and fitness (Vol. 1). Leeds: The Information Centre for Health and Social Care; 2009

31. Trost SG, Mclver KL, Pate RR. Conducting accelerometer-based activity assessments in field-based research. Med Sci Sports Exerc. 2005;37(11):S531-43.

32. Goldberg DP, Williams P. A user's guide to the General Health Questionnaire. Windsor, UK: NFER-Nelson; 1988

33. Van der Ploeg HP, Chey T, Korda RJ, Banks E, Bauman A. Sitting time and all-cause mortality risk in 222497 Australian adults. Arch Intern Med. 2012:172(6):494-500

34. Buman MP, Hekler EB, Haskell WL, Pruitt L, Conway TL, Cain KL, et al. Objective light-intensity physical activity associations with rated health in older adults. Am J Epidemiol. 2010;172(10):1155-65.

35. Eriksen L, Curtis T, Grønbæk M, Helge JW, Tolstrup JS. The association between physical activity, cardiorespiratory fitness and self-rated health. Prev Med. 2013;57(6):900-2

36. Galán I, Boix R, Medrano MJ, Ramos P, Rivera F, Pastor-Barriuso R, et al. Physical activity and self-reported health status among adolescents: a cross-sectional population-based study. BMJ Open. 2013;3(5):e002644.

37. Cimarras-Otal C, Calderón-Larrañaga A, Poblador-Plou B, González-Rubio F, Gimeno-Feliu LA, Arjol-Serrano JL, et al. Association between physical activity, multimorbidity, self-rated health and functional limitation in the Spanish population. BMC Public Health. 2014;17(14):1170.

38. Tremblay MS, Colley RC, Saunders TJ, Healy GN, Owen N. Physiological and health implications of a sedentary lifestyle. Appl Physiol Nutr Metab. 2010;35(6):725-40.

39. Teychenne M, Costigan SA, Parker K. The association between sedentary behaviour and risk of anxiety: a systematic review. BMC Public Health. 2015;19(15):513.

40. Chastin SF, Fitzpatrick N, Andrews M, DiCroce N. Determinants of sedentary behavior, motivation, barriers and strategies to reduce sitting time in older women: a qualitative investigation. Int J Environ Res Public Health. 2014;11(1):773-91.

41. Bailis DS, Segall A, Chipperfield JG. Two views of self-rated general health status. Soc Sci Med. 2003;56(2):203-17.

42. Manderbacka K, Lundberg O, Martikainen P. Do risk factors and health behaviours contribute to self-ratings of health? Soc Sci Med. 1999;48(12):1713-20

43. d'Uva B, Van Doorslaer E, Lindeboom M, O'Donnell O. Does reporting heterogeneity bias the measurement of health disparities? Health Econ. 2008;17(3):351-75

44. Wagner DC, Short JL. Longitudinal predictors of self-rated health and mortality in older adults. Prev Chronic Dis. 2014;11:130241.

\footnotetext{
Ready to submit your research? Choose BMC and benefit from:

- fast, convenient online submission

- thorough peer review by experienced researchers in your field

- rapid publication on acceptance

- support for research data, including large and complex data types

- gold Open Access which fosters wider collaboration and increased citations

- maximum visibility for your research: over 100M website views per year
}

At BMC, research is always in progress.

Learn more biomedcentral.com/submissions 